\title{
Panorama das indústrias galvânicas de Juazeiro do Norte, Ceará: com ênfase nos teores de metais-traço nos efluentes e resíduos sólidos
}

\author{
Overview of galvanic industries in Juazeiro do Norte, Brazil: \\ emphasis on trace metal content in effluents and solid waste
}

\begin{abstract}
Sheilla da Silva Melo Figueirêdo ${ }^{\oplus}$, Leonardo Alves Pinto ${ }^{1} \oplus$, Larissa Saraiva Oliveira' ${ }^{1}$,

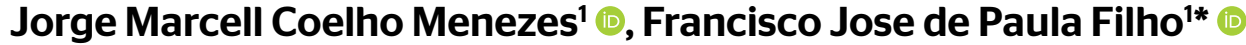

口-

\begin{abstract}
RESUMO
Os efluentes e resíduos industriais galvânicos são uma preocupação mundial, por terem em sua composição metais-traço altamente tóxicos, prejudiciais ao meio ambiente e à saúde humana. Neste artigo, é apresentado um panorama da indústria de semijoias folheadas de Juazeiro do Norte, Ceará, considerandose os processos de produção e a concentração de metais-traço nos efluentes, bem como o resíduo sólido galvânico, gerados pelo setor. Dados primários de produção foram obtidos em 11 empresas por meio de questionário técnico. As concentrações de metais-traço foram obtidas por espectrofotometria de absorção atômica de chama. Os resultados demonstraram ineficiência no tratamento dos efluentes para cobre, níquel, cromo, chumbo e zinco. As concentrações médias de metais no resíduo sólido galvânico foram de $239 \mathrm{~g}$ Cu kg'1, 99 g Zn kg', 23,8 g Ni kg'1, 6,6 g Pb kg', O,2 g Cr kg'1, 1,7 g Cd kg', 1,0 g Mn kg' e 8,2 g Fe kg'. Os resultados evidenciaram a necessidade da adoção de medidas para o controle de qualidade dos processos de tratamento dos efluentes, com vistas à sustentabilidade do setor.
\end{abstract}

Palavras-chave: metais-traço; lodo galvânico; efluentes; sustentabilidade.

\begin{abstract}
Galvanic industrial effluents and wastes are a worldwide concern, as they contain highly toxic trace metals that are harmful to the environment and human health. This article presents an overview of the clad semi jewelry industry in Juazeiro do Norte, state of Ceará, Brazil, considering the production processes and the concentration of trace metals in the effluents and galvanic sludge waste generated by the sector. Primary production data were obtained from 11 companies by a technical questionnaire. Trace metal concentrations were obtained by flame atomic absorption spectrophotometry. The results showed inefficiency in the treatment of effluents for copper, nickel, chrome, lead, and zinc. The average metal concentrations in the galvanic sludge waste were $239 \mathrm{~g} \mathrm{Cu} \mathrm{kg}^{-1}, 99 \mathrm{~g}$ Zn kg-1, 23.8 g Ni kg', $6.6 \mathrm{~g} \mathrm{~Pb} \mathrm{~kg}^{-1}, 0.2 \mathrm{~g} \mathrm{Cr} \mathrm{kg}^{-1}, 1.7 \mathrm{~g} \mathrm{Cd} \mathrm{kg}^{-1}, 1.0 \mathrm{~g} \mathrm{Mn} \mathrm{kg}$, and $8.2 \mathrm{~g} \mathrm{Fe} \mathrm{kg}^{-1}$. The results evidenced the need for adopting measures concerning quality control of the effluent treatment processes aiming at the sustainability of the sector
\end{abstract}

Keywords: trace metals; galvanic sludge; effluents; sustainability.

\section{INTRODUÇÃO}

Devido ao aumento geração de resíduos sólidos em todo o mundo, sua destinação final adequada constitui uma demanda crescente da sociedade (JACOBI \& BESEN, 2011). Resíduos perigosos são gerados e descartados constantemente por indústrias galvânicas no país, acarretando impactos diários ao meio ambiente. A galvanoplastia é considerada uma das grandes vilãs no que se refere à poluição do meio ambiente, por produzir o resíduo sólido galvânico (RSG), com alta carga poluente em volumes pequenos. Ao mesmo tempo, os processos galvânicos geram efluentes brutos com cargas poluentes diluídas em grandes volumes.
As espécies químicas poluentes estão relacionadas ao uso de desengraxantes, decapantes, cromatizantes e banhos concentrados de eletrodeposição exauridos, tornando-se crucial o adequado processo de tratamento das águas residuais (PORRAS, 2009; OLIVEIRA et al., 2018; LOSITSKA, 2018).

Os efluentes brutos gerados no processo de galvanoplastia devem ser tratados em estações de tratamento de efluentes (ETEs), com o objetivo de remover e/ou reduzir as concentrações de metais-traço presentes, visando alcançar aquelas previstas na legislação ambiental (BRASIL, 2011; CEARÁ, 2017). Os efluentes gerados nos processos industriais não devem causar ou ter potencial para gerar

'Universidade Federal do Cariri - Juazeiro do Norte (CE), Brasil.

*Autor Correspondente: francisco.filho@ufca.edu.br

Conflitos de interesse: os autores declaram não haver conflitos de interesse.

Financiamento: Fundação Cearense de Apoio ao Desenvolvimento Científico e Tecnológico (FUNCAP), processo n BP4-00172-00080.01.00/20)

Recebido: 22/02/2O19 - Aceito: 15/12/2O2O - Reg. ABES: 20190063 
efeitos tóxicos aos organismos aquáticos no corpo receptor (PASQUALINE, 2004). Para tanto, a legislação ambiental define limites específicos para as concentrações de metais-traço no efluente tratado.

Em geral, nos sistemas de tratamento de efluentes, os metais-traço dissolvidos são precipitados e, posteriormente, removidos por decantação, sedimentação ou, algumas vezes, por filtração. O RSG produzido no tratamento físico-químico de efluentes é potencialmente ecotóxico, por apresentar altos teores de metais-traço, caracterizando um passivo ambiental perigoso (classe I), conforme a NBR10004:2004 (ABNT, 2004). Segundo estimativas, o setor galvânico computa gastos com gerenciamento de resíduos equivalentes a $6 \%$ do seu custo total de produção (OLIVEIRA et al., 2018).

O automonitoramento é de responsabilidade do empreendedor e consiste na realização sistemática de medições ou observações de indicadores e limites especificados por tipo de fonte poluidora do meio ambiente. Essa prática tem por finalidade avaliar o desempenho dos sistemas de controle adotados e a eficácia das medidas mitigadoras dos impactos ambientais inerentes à atividade. Dessa forma, os efluentes somente poderão ser lançados, direta ou indiretamente, nos corpos receptores após o devido tratamento e desde que obedeçam às condições, aos padrões e às exigências dispostos na legislação (CEARÁ, 2017).

A sustentabilidade da atividade galvânica na Região Metropolitana do Cariri (RMC) depende da eliminação de impasses ambientais originados pela geração de seus efluentes líquidos e resíduos sólidos. Dentre esses impasses, destacamos a vulnerabilidade dos aquíferos, que fornecem água para cerca de 600 mil habitantes da região. Ao mesmo tempo, há de se levar em consideração a baixa capacidade de diluição dos rios receptores quanto aos metais-traço nos efluentes da atividade (COSTA et al., 2008; TAVARES et al., 2009).

Em regiões cujos recursos hídricos são limitados, como no semiárido do Nordeste do Brasil, há a necessidade de um rigoroso controle na qualidade dos processos de tratamento dos efluentes gerados pelo setor galvânico (ANA, 2012; COGERH, 2010). Particularmente na RMC, a cidade de Juazeiro do Norte destaca-se nacionalmente como um polo industrial metalúrgico responsável pela produção de semijoias folheadas. Nela predominam empresas de médio e pequeno porte, das quais muitas funcionam às margens do sistema de fiscalização ambiental, potencializando práticas de lançamento de efluentes fora dos padrões para descarte no meio ambiente (OLIVEIRA et al., 2018).

Diante do exposto, o presente estudo teve por objetivo apresentar um panorama do setor galvânico de semijoias folheadas da RMC quanto: a) aos processos de produção empregados pelas empresas; b) às concentrações de metais-traço nas amostras de efluentes e RSG das empresas investigadas; c) à eficiência nos processos de tratamento de efluentes e ao gerenciamento do RSG pelas empresas locais.

\section{METODOLOGIA}

\section{Área de estudo}

A cidade de Juazeiro do Norte faz parte da RMC e ocupa uma área de $249 \mathrm{~km}^{2}$. Segundo estimativas do IBGE (2017), a população local é de 270.383 habitantes (Figura 1). Na última década, a RMC tem despontado como polo de desenvolvimento econômico regional no Nordeste do Brasil. A cidade tem apresentado elevado potencial de crescimento econômico, confirmado pelos investimentos públicos e, sobretudo, privados, executados ou em processo de execução (EXAME,
2012; QUEIROZ, 2014; NASCIMENTO \& CHACON, 2016). Nesse cenário, o setor galvânico local, integra o setor metalúrgico, o qual representa $12,2 \%$ do total de indústrias instaladas na região (LIMA et al, 2018).

Apesar da importância para a economia local, os registros oficiais quanto ao número de empresas são inconsistentes. Atualmente, são 15 empresas do segmento de galvanoplastia de semijoias folheadas licenciadas junto ao órgão ambiental municipal. Registros da Federação das Indústrias do Estado do Ceará (FIEC) apontam um total de 22 empresas na região. Apesar de a RMC ter um distrito industrial desde 2009, as indústrias galvânicas locais encontram-se dispersas por todo o território do município.

\section{Levantamento de dados e coleta de amostras}

Os dados para a caracterização das empresas foram obtidos por meio de visitas técnicas para levantamento de informações em 11 indústrias do segmento galvânico em Juazeiro do Norte, CE. Como condição de confidencialidade, as empresas foram representadas por códigos de identificação de L1 a L11. Para obtenção de dados individuais de cada empresa, utilizou-se como instrumento de coleta de dados questionário técnico do tipo estruturado com questões pré-formuladas (CHAER et al., 2011; ALVES \& SEO, 2014). Esse método permitiu um levantamento mais uniforme das informações junto aos gestores das empresas. Foram levantadas informações que caracterizaram os empreendimentos quanto ao porte, aos processos galvânicos adotados na planta industrial, ao tratamento de efluentes e à destinação do RSG.

Durante as visitas técnicas, amostras de efluentes na forma bruta e RSGs foram obtidas. As amostras de efluente bruto foram coletadas nos tanques receptores localizados ao final da linha de produção de cada empresa. Algumas empresas realizam a separação do efluente bruto em tanques distintos, conforme a origem ácida ou alcalina. Nesses casos, volumes iguais de efluente bruto foram coletados e, posteriormente, misturados. Na mesma oportunidade, também foram obtidas amostras de efluentes tratados nas ETEs, após a decantação do RSG. Esse efluente corresponde ao líquido descartado na rede coletora. Em ambos os casos, a tomada de amostra ocorreu de maneira simples em uma única coleta. Portanto, considerando-se o método de amostragem adotado, esta pesquisa representa um "retrato do momento" em termos de processo de tratamento dos efluentes nas indústrias avaliadas. Os efluentes foram armazenados em garrafas PET de 1 L e conservada em temperatura controlada em refrigerador. Também foram obtidos, em tomada única, cerca de $1.000 \mathrm{~kg}$ de RSG em cada visita técnica realizada. O resíduo sólido foi armazenado em recipientes plásticos em temperatura ambiente até as etapas de processamento e análise.

\section{Análise dos efluentes e resíduo sólido galvânico}

Foram determinadas as concentrações de metais-traço cádmio $(\mathrm{Cd})$, cromo $(\mathrm{Cr})$, cobre $(\mathrm{Cu})$, ferro $(\mathrm{Fe})$, manganês $(\mathrm{Mn})$, níquel $(\mathrm{Ni})$, chumbo $(\mathrm{Pb})$ e zinco (Zn) nas amostras de efluentes e no RSG. As concentrações de metais-traço nos efluentes e no RSG foram determinados por meio de espectrometria de absorção atômica de chama (Varian Spectra A, modelo 50 B) na Central Analítica da Universidade Federal do Cariri. Para calibração, foram utilizados padrões certificados para cada metal-traço. Para determinação dos metais-traço, procedeu-se à análise de duplicatas de amostra.

A dosagem dos metais-traço nos efluentes foi realizada diretamente nas amostras ou, em alguns casos, após diluição prévia em solução de ácido nítrico $5 \%$. Por outro lado, o RSG foi processado por meio de secagem do material em 


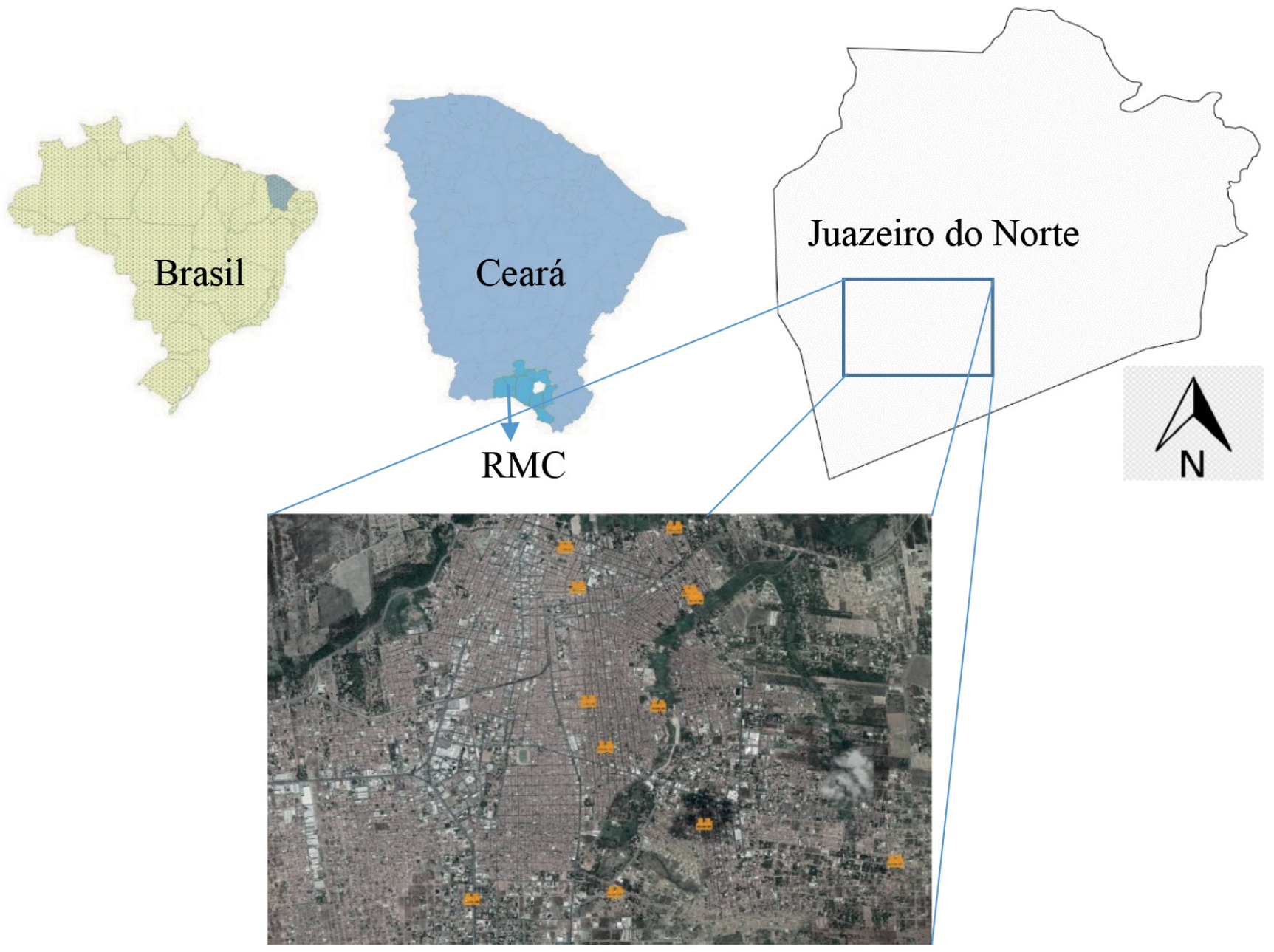

RMC: Região Metropolitana do Cariri. Fonte: elaborada pelos autores.

Figura 1 - Área de Estudo com distribuição das indústrias galvânicas em Juazeiro do Norte, Ceará.

estufa a $110^{\circ} \mathrm{C}$. Após a secagem, as amostras foram maceradas utilizando-se mão de gral e almofariz, sendo, posteriormente, peneiradas em abertura de $180 \mu \mathrm{m}$. O material prosseguiu para a etapa de extração dos metais-traço em meio ácido a partir de 1,000 g do RSG seco. Um volume de 25,0 $\mathrm{mL}$ de água régia $\left(3 \mathrm{HCl}: 1 \mathrm{HNO}_{3}\right)$ foi empregado em sistema fechado com recirculação à temperatura de $80^{\circ} \mathrm{C}$ por 2 horas (USEPA, 1998).

\section{Limites legais para lançamento de efluentes}

Os dados obtidos por meio do questionário técnico e a partir das análises em laboratório foram compilados e tratados em planilhas eletrônicas, utilizando-se o Microsoft Excel 2013 $3^{\circledR}$. Os resultados de concentração para os metais-traço nos efluentes foram então comparados aos padrões estabelecidos na legislação ambiental estadual, conforme a Tabela 1 (CEARÁ, 2017).

Para a verificação da conformidade dos dados obtidos com os padrões legais, foram adotados os limites preconizados para os parâmetros inorgânicos em efluentes não sanitários previstos na Resolução do Conselho Estadual do Meio Ambiente do Estado do Ceará (COEMA) nº 02 (CEARÁ, 2017). A resolução estadual dispõe sobre padrões e condições para lançamento de efluentes líquidos em corpos aquáticos ou diretamente no solo, conforme os parâmetros específicos por tipologia
Tabela 1 - Metais-traço e seus limites de tolerância para lançamento de efluentes não sanitários $\left(\mathrm{mg} \mathrm{L}^{-1}\right)$ em corpo hídrico e saturação no solo $\left(\mathrm{mg} \mathrm{kg}^{-1}\right)$.

\begin{tabular}{l|c|c}
\multirow{2}{*}{ Metal } & \multicolumn{2}{|c}{ Limite de tolerância* } \\
\cline { 2 - 3 } Cádmio & Corpo hidrico & Solo \\
\hline Chumbo & 0,2 & 1,3 \\
\hline Cobre dissolvido & 0,5 & 72 \\
\hline Cromo hexavalente & 1,0 & 60 \\
\hline Ferro solúvel & 0,1 & 75 \\
\hline Manganês solúvel & 15,0 & - \\
\hline Níquel & 1,0 & 30 \\
\hline Zinco & 2,0 & 300 \\
\hline
\end{tabular}

*Valores de referência da Resolução COEMA no 02/2017. Fonte: elaborada pelos autores.

de empreendimentos. Para efeito de comparações dos resultados obtidos para os efluentes reportados neste estudo, foram adotados os limites de tolerância (LT) para despejos em corpos hídricos receptores e/ou na rede coletora de esgotos. Nesse caso, o Cr representará uma exceção, visto que na regulamentação estadual 
é previsto LT para a forma hexavalente do metal, enquanto o presente estudo apresenta o elemento em sua fração total. Para os RSGs, levaremos em consideração o LT do respectivo metal, considerando a disposição no solo, conforme a Tabela 1.

\section{RESULTADOS E DISCUSSÃO}

\section{Caracterização das empresas investigadas}

A partir da aplicação do questionário técnico e considerando-se a autodeclaração da infraestrutura e do faturamento, foi possível classificar as empresas de acordo com o porte. Do total de empresas, 54,5\% declararam-se pertencentes à categoria micro e $36,4 \%$, à de pequeno porte. Com relação ao faturamento anual, $37 \%$ das empresas preferiram não responder a esse quesito, $9 \%$ indicaram faturamento anual abaixo de $\mathrm{R} \$ 100.000,00,36 \%$ entre $\mathrm{R} \$ 100.000,00$ e $\mathrm{R} \$ 1.000 .000,00$, enquanto $18 \%$ indicaram acima de $\mathrm{R} \$ 1.000 .000,00$. As células hachuradas na Tabela 2 representam os principais processos de folheação adotados pelas empresas de semijoias de Juazeiro do Norte, representadas pelos seus respectivos códigos de identificação.

Em relação ao processo produtivo, as opções mais assinaladas compreenderam douração, niquelação e cobreação (Tabela 2). O processo de douração é comum a todas as empresas, seguido de niquelação e cobreação, realizados por 91 e $82 \%$ das empresas, respectivamente. A prateação é realizada em 36,3\% e a cobertura por ródio, em $27,3 \%$. Este último é menos usual, mesmo nas empresas que declararam realizá-lo (L10 e L11), geralmente ocorrendo sob demanda específica.

\section{Principais processos galvânicos}

Os processos galvânicos adotados pelas empresas de Juazeiro do Norte contemplam etapas de tratamento de superfícies metálicas em soluções aquosas ácidas e alcalinas (Tabela 3). Simplificadamente, ocorrem em duas etapas: a limpeza e o preparo das peças com o uso de produtos químicos decapantes e desengraxantes, seguidos do revestimento com os metais desejados. As células hachuradas na Tabela 3 representam as principais etapas do processo produtivo adotadas nas empresas galvânicas investigadas na pesquisa.

O fluxograma representado na Figura 2 apresenta, em sequência, os processos mais utilizados pelas indústrias de semijoias folheadas em Juazeiro do Norte. Inicialmente, ocorre o desengraxe eletrolítico, etapa comum a todas as empresas pesquisadas. Uma solução de hidróxido de sódio para a remoção das graxas e dos óleos contidos nas peças é utilizada. A remoção dos óxidos existentes na superfície de peças, por solução decapante, é realizada em 55\% das empresas. Para garantir a aderência da camada metálica a ser depositada, a ativação ácida com solução de ácido sulfúrico (10\%) é realizada (ALVES \& SEO, 2014). Após a limpeza inicial das peças e do banho de ativação, ocorrem

Tabela 2 - Processos de folheação realizado nas empresas de semijoias de Juazeiro do Norte, Ceará.

\begin{tabular}{|c|c|c|c|c|c|c|c|c|c|c|c|}
\hline \multirow{2}{*}{ Processos } & \multicolumn{11}{|c|}{ Empresas } \\
\hline & $\mathrm{L} 1$ & L2 & L3 & $\mathrm{L} 4$ & $\mathrm{~L} 5$ & $\mathrm{~L} 6$ & L7 & L8 & L9 & L10 & L11 \\
\hline Niquelação & $x$ & $x$ & & $x$ & $x$ & $x$ & $x$ & $x$ & $x$ & $x$ & $x$ \\
\hline Cobreação & $x$ & $x$ & $x$ & $x$ & $x$ & & $x$ & $x$ & $x$ & & $x$ \\
\hline Douração & $x$ & $x$ & $x$ & $x$ & $x$ & $x$ & $x$ & $x$ & $x$ & $x$ & $x$ \\
\hline Prateação & & & & $x$ & & $x$ & & & & $x$ & $x$ \\
\hline Ródio & & & & $x$ & & & & & & $x$ & $x$ \\
\hline
\end{tabular}

Fonte: elaborada pelos autores.

Tabela 3 - Etapas do processo produtivo em indústrias galvânicas de semijoias folheadas de Juazeiro do Norte, Ceará.

\begin{tabular}{|c|c|c|c|c|c|c|c|c|c|c|c|}
\hline \multirow{2}{*}{ Etapas } & \multicolumn{11}{|c|}{ Empresas } \\
\hline & $\mathrm{L} 1$ & $\mathrm{~L} 2$ & L3 & $\mathrm{L} 4$ & L5 & L6 & L7 & L8 & L9 & L10 & L11 \\
\hline Desengraxante & $x$ & $x$ & $x$ & $x$ & $x$ & $x$ & $x$ & $x$ & $x$ & $x$ & $x$ \\
\hline Decapante & $x$ & $x$ & & $x$ & & & & $x$ & & $x$ & $x$ \\
\hline Cobre alcalino & $x$ & $x$ & $x$ & $x$ & $X$ & $x$ & $x$ & $x$ & $x$ & $x$ & $x$ \\
\hline Cobre ácido & $x$ & $x$ & $x$ & $x$ & $x$ & $x$ & $x$ & $x$ & $x$ & $x$ & $x$ \\
\hline Níquel & $x$ & $x$ & & $x$ & $x$ & $x$ & $x$ & $x$ & $x$ & & $x$ \\
\hline Pré-ouro & $x$ & $x$ & $x$ & $x$ & $x$ & $x$ & $x$ & $x$ & $x$ & $x$ & $x$ \\
\hline Ouro folheação & $x$ & $x$ & $x$ & $x$ & $x$ & $x$ & $x$ & $x$ & $x$ & $x$ & $x$ \\
\hline Cor final & $x$ & $x$ & $x$ & $x$ & $x$ & $x$ & $x$ & $x$ & $x$ & $x$ & $x$ \\
\hline Prata & & & & $x$ & & $x$ & & & & $x$ & $x$ \\
\hline Ródio & & & & $x$ & & & & & & $x$ & $x$ \\
\hline Água quente & $x$ & & & & & & & & $x$ & & \\
\hline Águas de lavagens* & $x$ & $x$ & $x$ & $x$ & $x$ & $x$ & $x$ & $x$ & $x$ & $x$ & $x$ \\
\hline Ativação ácida* & $x$ & $x$ & $x$ & $x$ & $x$ & $x$ & $x$ & $x$ & $x$ & $x$ & $x$ \\
\hline
\end{tabular}

*Acontecem entre as etapas. Fonte: elaborada pelos autores. 
as etapas dos banhos metálicos ( $\mathrm{Cu}, \mathrm{Ni}$ e ouro [Au]). Esses banhos metálicos são intercalados por lavagens com água, visando evitar a contaminação dos banhos de diferentes cubas eletrolíticas.

O processo de recobrimento metálico acontece por imersão das peças em banhos com diferentes soluções eletrolíticas, submetidas à corrente elétrica contínua de baixa tensão (entre 5 e 6V). A deposição metálica tem início com o processo chamado de Cualcalino, o qual confere à peça nivelamento e elimina imperfeições de superfície. É realizado em solução contendo sais de cianeto de $\mathrm{Cu}$, cianeto de sódio ou potássio, formando compostos solúveis de $\mathrm{Cu}$. Em seguida, o banho de $\mathrm{Cu}$ ácido confere acabamento e brilho de superfície. Nele utiliza-se solução eletrolítica contendo sulfato de $\mathrm{Cu}$, ácido sulfúrico e ácido clorídrico (FURTADO, 2003; OLIVEIRA et al., 2018).

Com base no levantamento dos dados, verificou-se que $82 \%$ das empresas utilizam o banho de Ni. Esse banho visa conferir proteção adicional contra corrosão às peças. Nele é empregada uma solução eletrolítica contendo sulfato de níquel, cloreto de níquel e ácido bórico. O banho de pré-ouro é aplicado em seguida, para melhorar a aderência do Au nos banhos subsequentes de folheação. O processo produz depósitos de Au com alto brilho e resistência. A última etapa da folheação (cor final) tem por objetivo conferir padrão de tonalidade homogênea, resistência à perda de brilho e mudanças de cor em função da oxidação.

\section{Efluente e resíduo sólido gerados nos processos de recobrimento galvânico}

Considerando-se as etapas descritas no fluxograma (Figura 2), o efluente bruto gerado é proveniente dos banhos químicos, da água de lavagem e dos produtos auxiliares. O efluente bruto geralmente é colorido, em alguns casos com temperatura superior à do ambiente, e libera vapores. Seu $\mathrm{pH}$ geralmente atinge os extremos ácido ou alcalino. Algumas empresas realizam separação dos efluentes ácidos e alcalinos previamente ao processo de tratamento (Tabela 4).

O levantamento realizado demonstrou que $27 \%$ das empresas realizam a separação dos efluentes ácidos e alcalinos em tanques distintos, enquanto $73 \%$ das empresas encaminham todos para um tanque comum. Na Tabela 4 , as células hachuradas indicam os procedimentos adotados pelas empresas no armazenamento do efluente bruto.

Para o tratamento do efluente bruto, é comum realizar ajuste do $\mathrm{pH}$, oxidação do cianeto e sedimentação/decantação. Verificou-se que 72,2\% das empresas utilizam o ajuste do $\mathrm{pH}$ e, 54,5\% realizam a oxidação de cianeto e a sedimentação/ decantação. O processo de neutralização é realizado por $45,4 \%$ das empresas, enquanto $36,3 \%$ utilizam a filtração, a redução de sulfato e a coagulação. O processo menos frequente é a floculação, utilizada em apenas 19\% das empresas.

Conforme os dados compilados, $73 \%$ das empresas afirmam realizar análises periódicas dos seus efluentes, enquanto $18 \%$ não realizam. Apenas uma empresa reutiliza a água resultante do tratamento nos próprios banhos e as demais encaminham o efluente tratado diretamente à rede coletora. Em nenhuma das empresas avaliadas é realizado o descarte de efluentes diretamente em cursos hídricos.

Em relação ao RSG, a maioria das empresas utiliza leitos de secagem para retirada de umidade. Destas, $45 \%$ secam o material ao ar livre, enquanto $27 \%$ o fazem em áreas cobertas. O uso de filtro-prensa no tratamento do resíduo é uma prática pouco adotada, ocorrendo em apenas $18 \%$ dos empreendimentos. Em um caso específico, verificou-se o armazenamento de resíduo sem a retirada da umidade.

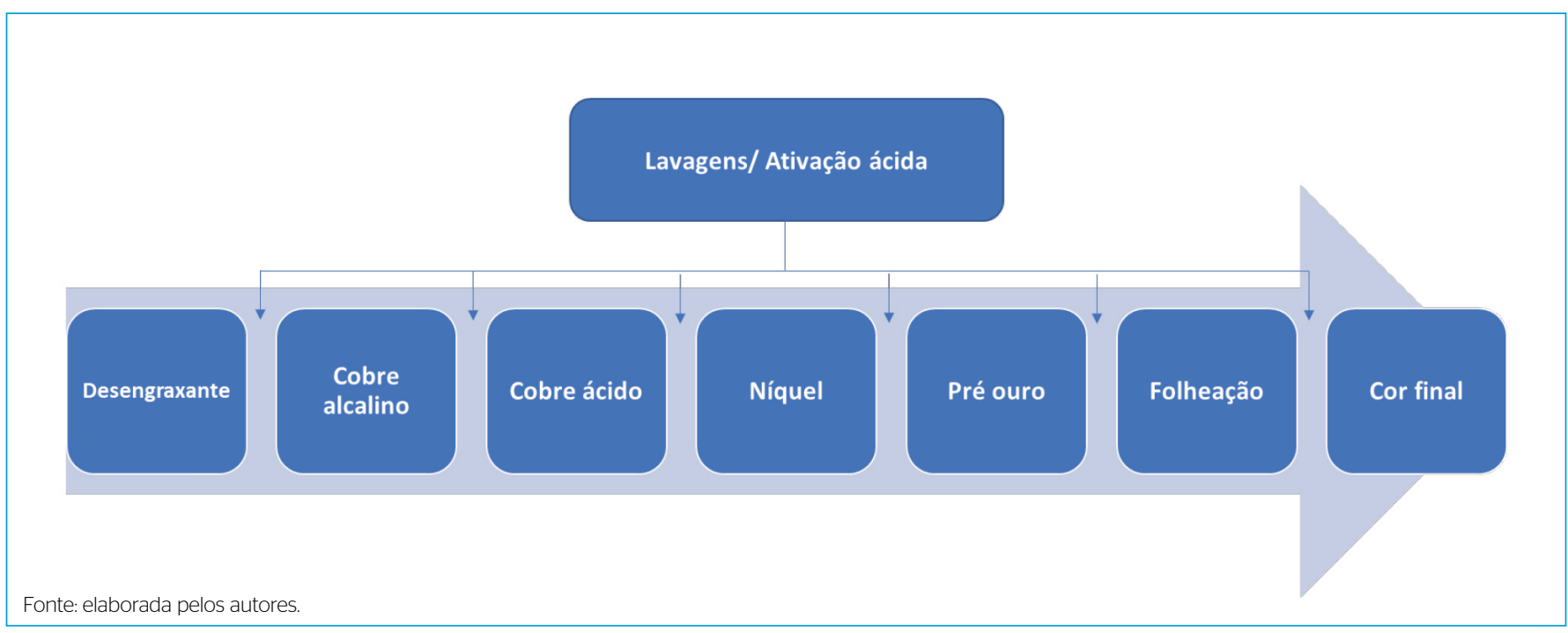

Figura 2 - Fluxograma dos processos galvânicos adotados nas indústrias de semijoias de Juazeiro do Norte, Ceará.

Tabela 4 - Separação dos efluentes para tratamento nas indústrias de semijoias de Juazeiro do Norte, Ceará.

\begin{tabular}{|c|c|c|c|c|c|c|c|c|c|c|c|}
\hline \multirow{2}{*}{ Tanques } & \multicolumn{11}{|c|}{ Empresas } \\
\hline & $\mathrm{L} 1$ & $\mathrm{~L} 2$ & L3 & L4 & L5 & $\mathrm{L} 6$ & $\mathrm{L7}$ & L8 & L9 & L10 & L11 \\
\hline Efluentes ácidos & $x$ & $x$ & & & & $x$ & & & & & \\
\hline Efluentes alcalinos & $x$ & $x$ & & & & $x$ & & & & & \\
\hline Sem separação & & & $x$ & $x$ & $x$ & & $x$ & $x$ & $x$ & $x$ & $x$ \\
\hline
\end{tabular}

Fonte: elaborada pelos autores. 
Após a secagem, o RSG é estocado em tambores plásticos, para posterior destinação. Segundo estimativas da indústria local, a maior parte dos empreendimentos (63,3\%) tem geração anual de RSG em torno de $150 \mathrm{~kg}$. Nas empresas com maior infraestrutura instalada, há geração entre 300 e $600 \mathrm{~kg}$ anuais de resíduo. Por outro lado, $18 \%$ das empresas consultadas não apresentaram dados ou estimativas de produção anual de RSG. Conforme a NBR 12235, o acondicionamento de resíduos perigosos, como forma temporária de espera para reciclagem, recuperação, tratamento e/ou disposição final, pode ser realizado em contêineres, tambores, tanques e/ou a granel (ABNT, 1992). A prática comum realizada pelas empresas do setor galvânico de semijoias folheadas de Juazeiro do Norte é estocar o RSG em tambores plásticos com capacidade de $250 \mathrm{~L}$ até a coleta e a destinação para empresas recicladoras.

\section{Concentração de metais-traço nos efluentes}

A Figura 3 apresenta as concentrações de metais-traço nos efluentes bruto e tratado nas empresas investigadas. Evidencia-se a tendência de remoção de cada metal-traço no efluente bruto. Verifica-se que a eficiência na remoção de metais-traço é variável por empresa e, em alguns casos, há elevação do poluente no efluente tratado, cenário observado para os metais $\mathrm{Ni}$ (L7), $\mathrm{Fe}$ (L3), $\mathrm{Pb}$ (L2, L3, L4, L7 e L9) e Cr (L7). Em termos de valor médio das concentrações para cada metal-traço, a ordem crescente estabelecida foi $[\mathrm{Cd}]<[\mathrm{Cr}]<[\mathrm{Pb}]<[\mathrm{Mn}]$ $<[\mathrm{Fe}]<[\mathrm{Ni}]<[\mathrm{Zn}]<[\mathrm{Cu}]$.

A predominância de $\mathrm{Cu}$ no efluente bruto é consequência de sua presença majoritária nos banhos eletrolíticos preparatórios para douração (Figura 2). O metal também está presente nas ligas metálicas das peças que passam pelo processo de recobrimento. Observou-se que o $\mathrm{Cu}$ apresentou altas concentrações no efluente bruto, em alguns casos superando em até 262 vezes o limite de tolerância para despejo em corpos hídricos receptores, conforme estabelecido na legislação ambiental estadual (CEARÁ, 2017). Concentrações de Cu acima do limite de tolerância foram evidenciadas em $100 \%$ dos resultados. As empresas L1, L7 e L10 apresentaram as maiores concentrações de $\mathrm{Cu}$ no efluente bruto, 262,2; 165,9 e 157,6 $\mathrm{mg} \mathrm{L}^{-1}$, respectivamente.

Em 27\% dos empreendimentos, a concentração de $\mathrm{Zn}$ no efluente bruto foi superior ao LT (L1, L6 e L10), chegando a excedê-lo em até 62 vezes. Em L5 não houve presença do metal no efluente bruto e as maiores concentrações foram determinadas em L6 e L10: 123,1 e 68,9 mg L $\mathrm{L}^{-1}$, respectivamente. Como observado, o Zn é o segundo metal-traço mais abundante no efluente bruto. Sua presença está relacionada, principalmente, à constituição da liga metálica do tipo Zamak. Essa liga é amplamente utilizada pela indústria local na fundição de peças para produção de bijuterias. O nome da liga advém dos metais na língua alemã, Zink-Aluminium-Magnesium-Kupfer ( $\mathrm{Zn}, \mathrm{Al}, \mathrm{Mg}$ e Cu, respetivamente).

A excedência do Ni em relação ao LT no efluente bruto foi verificada em $82 \%$ dos empreendimentos (exceto L3 e L10). As maiores concentrações de $\mathrm{Ni}$ foram determinadas nos efluentes de $\mathrm{L} 6\left(17,9 \mathrm{mg} \mathrm{L}^{-1}\right)$, valor 9 vezes mais elevado do que o LT (Tabela 1), seguidas de L8 e L9 (13 $\left.\mathrm{mg} \mathrm{L}^{-1}\right)$ e L5 (10,9 $\left.\mathrm{mg} \mathrm{L}^{-1}\right)$.

Todas as empresas apresentaram concentrações de $\mathrm{Fe}$ abaixo do limite de tolerância. O efluente bruto da empresa L6 foi o que apresentou maior concentração de Fe, 7,7 mg L $\mathrm{m}^{-1}$. Em cinco empresas constatou-se a presença de Mn nos efluentes brutos em concentrações detectáveis. Dentre elas, 27\% apresentaram excedência do valor de LT. As maiores concentrações foram verificadas em L1 (6,1 $\left.\mathrm{mg} \mathrm{L}^{-1}\right), \mathrm{L} 10\left(1,9 \mathrm{mg} \mathrm{L}^{-1}\right)$ e L11 $\left(1,5 \mathrm{mg} \mathrm{L}^{-1}\right)$.
Verificou-se presença de $\mathrm{Pb}$ em todas as amostras de efluentes brutos, e em $36 \%$ dos casos superou o valor de LT. As maiores concentrações de $\mathrm{Pb}$ nos efluentes brutos foram encontradas em amostras obtidas em L3 e L11 (0,8 mg $\left.\mathrm{L}^{-1}\right)$, L2 (1,3 mg L $\left.{ }^{-1}\right)$ e L4 (1,6 mg L $\left.{ }^{-1}\right)$. Esse resultado, em particular, deve ser avaliado quanto às implicações sobre a origem do metal-traço para os efluentes. Provavelmente, a presença do $\mathrm{Pb}$ pode estar relacionada a traços do metal nas ligas metálicas das peças a serem folheadas e/ou a impurezas presentes nos sais das soluções eletrolíticas, ou mesmo em componentes de suporte das peças nos banhos eletrolíticos.

As empresas L5, L6, L7, L8, L9, L10 e L11 apresentaram Cr total em seus efluentes com concentrações variando entre 0,38 e $0,43 \mathrm{mg} \mathrm{L}^{-1}$. Como se realiza o processo de cromação nas empresas pesquisadas, a presença do metal nos efluentes brutos provavelmente está relacionada a resíduos nos insumos ou nas ligas metálicas das peças que passam pelos banhos. Ressalta-se que os resultados apresentados correspondem às concentrações de $\mathrm{Cr}$ total, enquanto a legislação apresenta valores limite para $\mathrm{Cr}$ hexavalente. Sendo assim, não foram realizadas comparações em relação às concentrações de Cr e ao LT descrito na legislação ambiental estadual.

Apenas em um empreendimento (L1) a concentração de Cd (0, 4 mg $\mathrm{L}^{-1}$ ) superou o LT, ou seja, essa ocorrência corresponde a $9 \%$ das amostras analisadas. Essa informação indica ausência ou baixa concentração do metal-traço nas ligas metálicas das peças. Particularmente o $\mathrm{Cd}$ e o $\mathrm{Pb}$ são alvo de atenção das agências de fiscalização, principalmente em virtude da alta toxicidade à vida (PAIS et al., 2018). Por exemplo, quando o revestimento metálico das peças não é de boa qualidade, há risco de absorção cutânea do Cd, tendo efeitos acumulativos no organismo humano. Embora a absorção por meio da pele não seja uma via significativa de entrada do metal no corpo humano, órgãos de fiscalização no Brasil e em outros países apresentam limites rígidos de concentração nas peças. Para joias e bijuterias, a Portaria $n^{\circ} 43$, do Instituto Nacional de Metrologia, Qualidade e Tecnologia (INMETRO), estipula o limite máximo permitido por peso de peça igual a $0,03 \%$ para $\mathrm{Pb}$ e $0,01 \%$ para o Cd (MDIC, 2016). Todavia, na presente pesquisa não foram avaliadas as concentrações de $\mathrm{Pb}$ e Cd nas peças da linha de produção.

Como evidenciado na Figura 3, em algumas empresas, os resultados demonstraram que, mesmo após o tratamento por precipitação química, vários metais-traço persistiram em solução. Em uma análise geral dos resultados analíticos obtidos, as concentrações médias para os metais-traço seguem a ordem crescente $[\mathrm{Cd}]=[\mathrm{Fe}]<[\mathrm{Cr}]<[\mathrm{Mn}]<[\mathrm{Pb}]<[\mathrm{Zn}]<[\mathrm{Ni}]<[\mathrm{Cu}]$.

Concentrações de $\mathrm{Cu}$ em valores acima do LT foram verificadas em $54,5 \%$ das empresas pesquisadas. Por exemplo, em L1, apesar de a redução atingir 62\% de rendimento, ainda assim, a concentração de $\mathrm{Cu}$ é cerca de 60 vezes superior ao LT. Nessa condição, o descarte nos corpos hídricos ou em rede coletora de esgoto não é recomendado. Em L11 ocorre situação semelhante, com rendimento na redução da concentração em torno de $54 \%$. Mesmo assim, a concentração final de $\mathrm{Cu}\left(41,6 \mathrm{mg} \mathrm{L}^{-1}\right)$ é 42 vezes superior ao LT. Apenas L2, L3, L8 e L10 conseguiram precipitar $100 \%$ do metal no processo de tratamento químico realizado. Em L5 e L7 foram obtidas reduções significativas, superiores a $98 \%$, seguidos por L6, com remoção de até $90 \%$ do Cu em solução. Mesmo nesses casos, o limite de tolerância da legislação ambiental não foi alcançado, o que demonstra a necessidade de maior controle no processo de tratamento do efluente bruto realizado nas ETEs das empresas. 

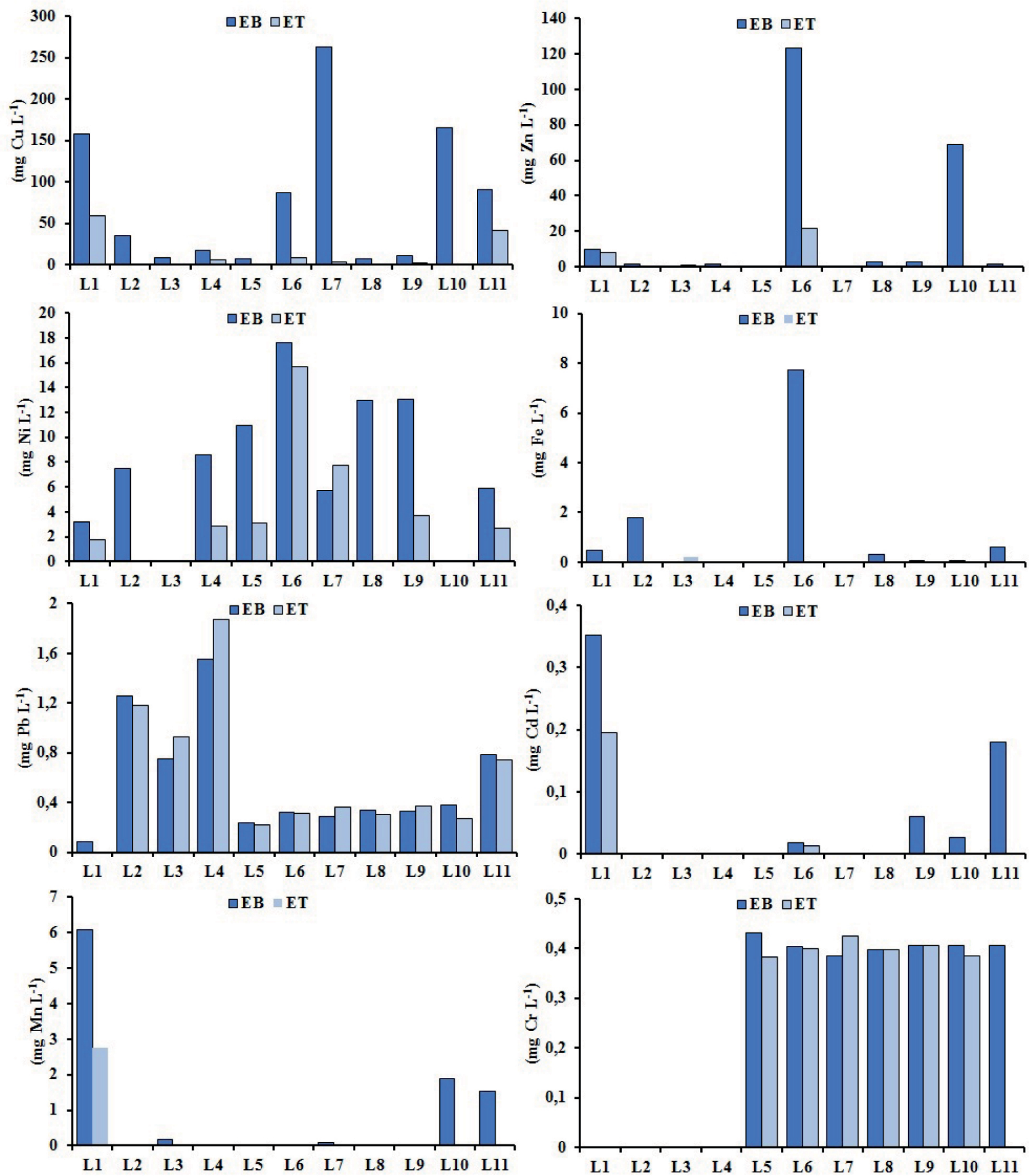

EB: efluente bruto; ET: efluente tratado; L1-L2: indústrias do segmento galvânico em Juazeiro do Norte. Fonte: elaborada pelos autores.

Figura 3 - Concentrações de metais-traço nos efluentes bruto e tratado e após tratamento químico nas indústrias de semijoias de Juazeiro do Norte, Ceará.

Concentrações de Ni acima do LT foram registradas em 54,5\% das empresas. A remoção de Ni no efluente após tratamento químico ocorreu apenas em L8. Neste empreendimento, a concentração final de Cu foi igual a 0,07 mg $\mathrm{L}^{-1}$. Como indicado na Figura 3, em L3 e L10 não houve detecção do metal no efluente bruto, situação que se repetiu no efluente tratado. Nas demais empresas, o rendimento na remoção do metal variou entre 11 e $99 \%$. Seguindo-se a ordem decrescente de remoção, temos: L2 (99\%), L5 e L9 (72\%), L4 (67\%), L11 (54\%), L1 (47\%) e L6 (11\%). Superaram o valor de LT para descarte do 
efluente as amostras analisadas das empresas $\mathrm{L} 4\left(2,8 \mathrm{mg} \mathrm{L}^{-1}\right), \mathrm{L} 5\left(3,1 \mathrm{mg} \mathrm{L}^{-1}\right)$, L6(15,7 mg L $\left.\mathrm{m}^{-1}\right), \mathrm{L} 7\left(7,7 \mathrm{mg} \mathrm{L}^{-1}\right), \mathrm{L} 9\left(3,7 \mathrm{mg} \mathrm{L}^{-1}\right)$ e L11 $\left(2,7 \mathrm{mg} \mathrm{L}^{-1}\right)$. Por outro lado, em L7 houve aumento de 37\% na concentração de Ni no efluente tratado.

A concentração de Zn no efluente tratado superou o LT nas empresas L1 $\left(8,3 \mathrm{mg} \mathrm{L}^{-1}\right)$ e L6 (21,4 $\left.\mathrm{mg} \mathrm{L}^{-1}\right)$. A menor eficiência de remoção ocorreu em L1, atingindo apenas $14 \%$ no efluente tratado. Registrou-se remoção total do metal-traço nos efluentes das empresas L7, L8, L9, L10 e L11. Significativa remoção também foi observada em L2, L4 e L6, alcançando eficiência de 98, 96 e 82,6\%, respectivamente.

$\mathrm{O} \mathrm{Pb}$ foi completamente removido do efluente bruto apenas na empresa L1. Nos demais empreendimentos, a redução variou entre 4\% (L6) e 28\% (L10). Em alguns casos, houve elevação nas concentrações de $\mathrm{Pb}$ no efluente após tratamento químico (L3, L4, L7 e L9). Nesses casos, provavelmente falhas no controle e no monitoramento do processo de precipitação química realizado nas ETEs podem ter ocasionado aumento de solubilidade do metal em solução.

Mais eficiente foi a remoção de Mn do efluente bruto, o que ocorreu em $86 \%$ das empresas. Concentração acima do LT foi verificada apenas em L1 (2,8 mg $\mathrm{L}^{-1}$ ), espelhando a baixa remoção do metal no efluente, que, neste caso, alcançou apenas $54 \%$ de rendimento.

O rendimento de remoção de Cr total em L11 foi de 100\%, enquanto nas demais empresas as taxas obtidas foi de 1\% (L6), 5,2\% (L10) e 11,5\% (L5). Em L7 houve aumento nas concentrações do efluente tratado $\left(0,43 \mathrm{mg} \mathrm{L}^{-1}\right)$, em relação ao bruto $\left(0,38 \mathrm{mg} \mathrm{L}^{-1}\right)$. Apesar de a cromação não ser um processo realizado nas empresas investigadas, sua presença nos efluentes da produção pode estar relacionada a traços do metal nos insumos ou nas ligas metálicas das peças e suportes levados aos banhos eletrolíticos.

A remoção total do Fe nos efluentes galvânicos foi observada em L1, L2, L6, L7, L8, L10 e L11, evidenciando eficiência no processo de precipitação química em relação a esse metal. Nas empresas L3, L4, L5 e L7 não houve presença de Fe nos efluentes brutos. Porém, após o tratamento, observou-se concentração máxima igual a $0,2 \mathrm{mg} \mathrm{L}^{-1} \mathrm{em} \mathrm{L3}$. Sua presença provavelmente advém de contaminantes nos insumos empregados no processo de tratamento ou da corrosão de peças metálicas presentes no tanque de precipitação.

Concentrações de cádmio somente foram detectáveis em cinco empresas. Destas, apenas três (L9, L10 e L11) conseguiram remover 100\% do elemento no processo de tratamento dos efluentes. Em L1 houve eficiência de redução de $45 \%\left(0,2 \mathrm{mg} \mathrm{L}^{-1}\right)$ e em L6, de $30 \%\left(0,01 \mathrm{mg} \mathrm{L}^{-1}\right)$.

\section{Considerações sobre a eficiência do tratamento químico dos efluentes}

As práticas atuais de tratamento de efluentes realizadas pelo segmento industrial de semijoias folheadas de Juazeiro do Norte utilizam variações de uma metodologia bastante difundida em outras regiões do país. Esse método convencional de tratamento de efluentes industriais contendo metais em solução aquosa consiste na elevação do $\mathrm{pH}$ até valores acima de 9,0, promovendo condições de baixa solubilidade dos hidróxidos dos metais que se precipitam sob a forma de hidróxidos ou complexos diversos (PEREIRA NETO et al., 2008). Portanto, o resíduo sólido gerado apresenta altos teores de metais e outros componentes tóxicos em sua constituição.

Uma das vantagens do processo de precipitação química é seu baixo custo em função de utilizar insumos comerciais, como, por exemplo, a cal como agente alcalinizante. A técnica de remoção consiste na insolubilização, supersaturação e posterior precipitação dos metais por ajuste do $\mathrm{pH}$, com precipitação na forma de hidróxidos metálicos insolúveis coloidais. Seguindo-se as etapas de coagulação/floculação para sua separação da fase líquida residual (RIBEIRO et al., 2006; KURNIAWAN et al., 2006). É, portanto, fundamental o controle de $\mathrm{pH}$ para efetiva remoção dos contaminantes nos efluentes. Fatores como temperatura, agitação, tempo de repouso e concentração do agente precipitante também interferem no rendimento do processo. Por exemplo, o excesso de $\mathrm{NaOH}$ (agente precipitante) pode acarretar aumento da solubilidade dos metais-traço em função da formação de íons complexos, os quais podem se ligar a outros íons de carga oposta ou a moléculas de água (PEREIRA NETO et al., 2008). A ocorrência de reações paralelas devido à superdosagem de agentes alcalinizantes corrobora resultados insatisfatórios. Isso pode reduzir a eficiência do tratamento devido à formação de hidroxocomplexos solúveis.

A elevação nas concentrações de alguns metais-traço nos efluentes de algumas empresas pode ser atribuída a inadequações no processo de tratamento adotado e no monitoramento deficiente das condições de operação em suas ETEs, levando, consequentemente, à ressolubilização de alguns metais-traço, como observado para Ni (L7), Zn (L3), Pb (L3, L4, L7 e L9), Cr (L7) e Fe (L3).

\section{Concentração de metais-traço no resíduo sólido galvânico}

Em geral, os resultados da análise de poluentes metálicos no RSG evidenciaram altos teores de metais-traço no material, confirmando sua classificação como Resíduo Perigoso Classe I (ABNT, 2004).

As faixas de concentração de metais-traço no RSG analisado variaram entre 123 e $489 \mathrm{~g} \mathrm{Cu} \mathrm{kg}^{-1} ; 0,3$ e $59 \mathrm{~g} \mathrm{Ni} \mathrm{kg}^{-1} ; 0,3$ e $62 \mathrm{~g} \mathrm{Zn} \mathrm{kg}^{-1} ; 0,2$ e $25 \mathrm{~g} \mathrm{~Pb} \mathrm{~kg}^{-1}$; 0,03 e $0,8 \mathrm{~g} \mathrm{Cr} \mathrm{kg}^{-1}$; 0,0 e 1,4 $\mathrm{g} \mathrm{Cd} \mathrm{kg}^{-1} ; 0,03$ e 2,9 $\mathrm{g} \mathrm{Mn} \mathrm{kg}^{-1}$; e 1,1 e 6,6 $\mathrm{g} \mathrm{Fe} \mathrm{kg}^{-1}$. Concentrações de $\mathrm{Cu}$ e $\mathrm{Pb}$ foram mais elevadas no resíduo empresa L3 (489 e $25 \mathrm{~g} \mathrm{~kg}^{-1}$, respectivamente). Ni apresentou maior concentração na amostra da empresa L4 (59 $\left.\mathrm{g} \mathrm{kg}^{-1}\right)$, enquanto $\mathrm{Zn}$ teve seu maior registro em L10 (62 $\left.\mathrm{mg} \mathrm{kg}^{-1}\right)$. Em L11 foram identificados os maiores teores de $\mathrm{Cr}\left(0,9 \mathrm{~g} \mathrm{~kg}^{-1}\right)$ e Fe $\left(6,6 \mathrm{~g} \mathrm{~kg}^{-1}\right)$. Os metais-traço $\mathrm{Cd}$ e $\mathrm{Mn}$ alcançaram maiores concentrações nas empresas L1 $\left(0,8 \mathrm{~g} \mathrm{~kg}^{-1}\right)$ e L10 $\left(2,9 \mathrm{~g} \mathrm{~kg}^{-1}\right)$, respectivamente, conforme demonstrado na Figura 4. Os metais mais associados aos resíduos dos processos galvânicos nas empresas da RMC foram $\mathrm{Cu}$, Ni e Zn.

Ao agregar os resultados para obter o valor médio da concentração de cada metal-traço no RSG, estabelece-se a ordem crescente de relevância: $[\mathrm{Cr}]<[\mathrm{Mn}]$ $<[\mathrm{Cd}]<[\mathrm{Pb}]<[\mathrm{Fe}]<[\mathrm{Zn}]<[\mathrm{Ni}]<[\mathrm{Cu}]$. Esse resultado reflete a representatividade de cada elemento nas diferentes etapas de recobrimento metálico. Por exemplo, nas etapas de produção (Tabela 3) e no fluxograma de processos (Figura 2) evidenciou-se o uso intenso de $\mathrm{Cu}$ e Ni no recobrimento metálico, repercutindo em altos teores desse elemento nos efluentes e no resíduo gerados (OLIVEIRA et al., 2018).

A Lei n 12.305/10 institui a Política Nacional de Resíduos Sólidos (PNRS), que definiu os parâmetros legais para a destinação final de resíduos (BRASIL, 2010). Dessa forma, toda empresa passou a ser responsável em tratar os resíduos que gera, sendo que o descarte irregular é passível de sanções e penalidades. Nesse contexto, os resíduos industriais exigem procedimentos específicos para sua eliminação, nos quais, a partir da classificação, determina-se a destinação. Esse tratamento específico não diz respeito apenas ao descarte, mas também ao transporte (ABNT, 2004).

O RSG é um passivo ambiental perigoso e requer a adoção de práticas de gerenciamento adequadas, para minimizar os impactos ao meio ambiente. Do ponto de vista econômico, o gerenciamento de resíduos Classe I é oneroso, 


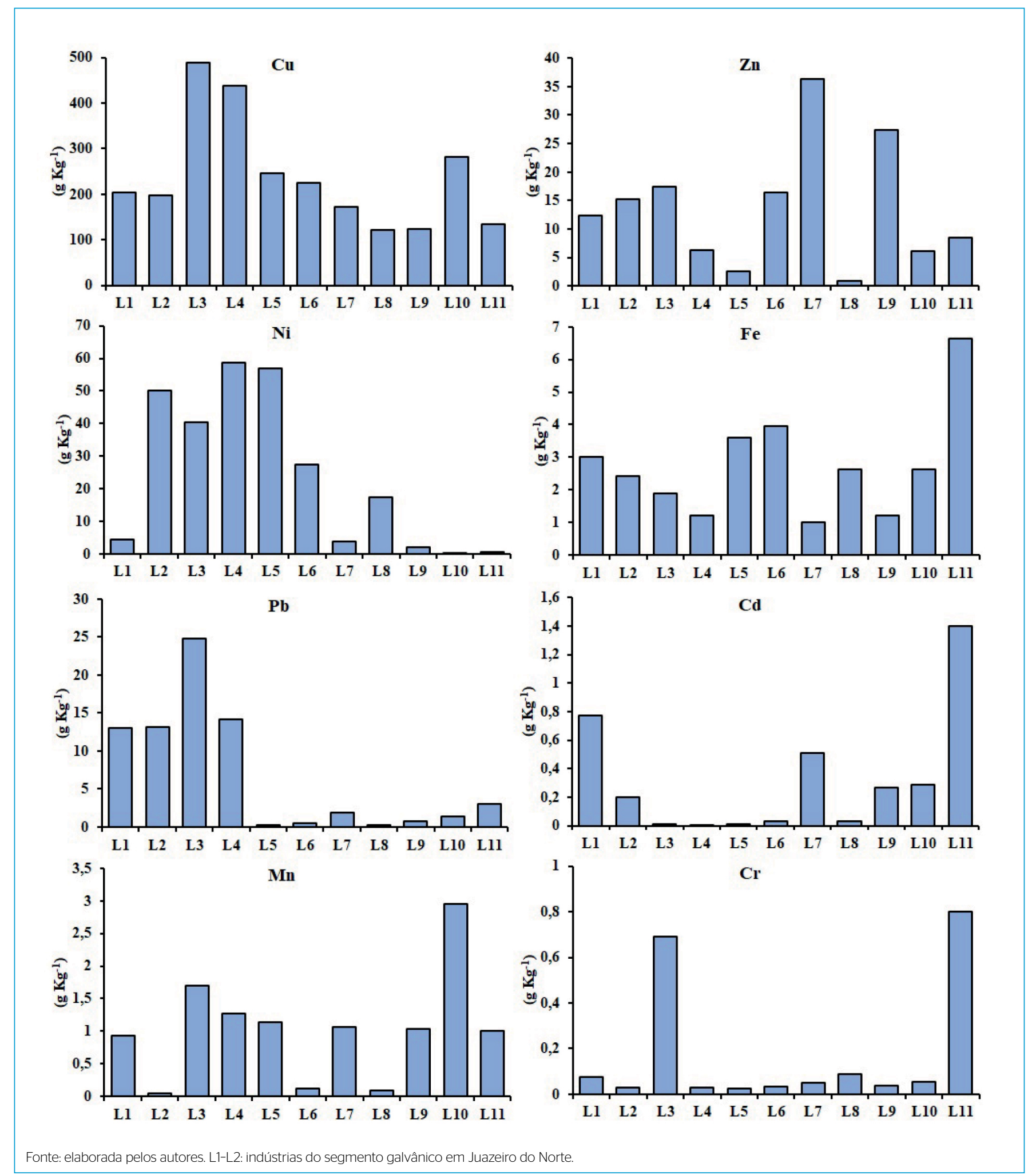

Figura 4 - Concentração de metais traço no resíduo sólido galvânico das indústrias de semijoias de Juazeiro do Norte, Ceará.

principalmente para empresas de pequeno e médio porte, como registrado nesta pesquisa. $\mathrm{O}$ alto custo associado ao transporte, ao tratamento e à disposição final, bem como a falta de espaço físico nas instalações industriais para armazenamento, representam dificuldades presentes na prática diária das empresas da região. Soluções como o coprocessamento, que consiste na destruição térmica de resíduos em fornos de cimento, apresentam dificuldades econômicas e de logística para serem adotadas pelo setor local, principalmente por seu custo elevado (FURTADO, 2003; ROCHA et al., 2011).

A forma encontrada (não só pelas empresas que integraram esta pesquisa mas também pelo setor galvânico instalado na RMC) para garantir a destinação 
adequada de seus resíduos foi a formação de um "consórcio". O RSG armazenado é, então, destinado a uma multinacional recicladora de resíduos industriais metálicos e de tratamento de superfície. Com periodicidade variável, e mediante análise laboratorial prévia, a multinacional verifica se o material de cada empresa galvânica local contém metais recuperáveis em quantidade suficiente para serem reciclados. Uma vez recolhidos pela sucursal da multinacional no Brasil, os RSGs são, então, exportados para usinas de reciclagem localizadas nos Estados Unidos, na Europa e na Ásia. O RSG e os outros resíduos metálicos são usados na produção de concentrados metálicos, que são commodity internacional da indústria de metais não ferrosos.

Como alternativa para a destinação do RSG, estudos apontam o desenvolvimento de produtos de cerâmica aditivados com o referido material. Pesquisa recente de Teloeken (2011) demonstrou a possibilidade da produção de corpos cerâmicos com formulações aditivadas com RSG. Essas composições poderiam ser aplicadas em telhas, blocos cerâmicos e placas cerâmicas de revestimento, considerando-se que na RMC estão instaladas indústrias cerâmicas.

\section{CONCLUSÕES}

A compilação dos dados obtidos por meio do questionário técnico permitiu avaliar o porte das indústrias investigadas, predominando empresas de micro e pequeno porte. Douração, cobreação e niquelação são os principais processos utilizados na produção, e o tratamento dos efluentes por precipitação química é padrão nas empresas pesquisadas.

Considerando-se a variação nas concentrações entre o efluente bruto e o tratado quimicamente, foi possível constatar que em parte das empresas investigadas houve baixa eficiência de remoção de metais-traço presentes na solução. A remoção foi ineficiente principalmente para os metais traço $\mathrm{Pb}, \mathrm{Ni}, \mathrm{Cu}$ e $\mathrm{Cr}$, que apresentaram, ao final da precipitação química, concentrações ainda superiores aos padrões máximos estabelecidos pela legislação estadual.

No RSG, o Cu, o Ni e o Zn foram os elementos majoritários em relação aos demais metais avaliados. O gerenciamento desse resíduo é realizado de forma conjunta pelas indústrias avaliadas, sendo destinado à reciclagem, para recuperação de metais de interesse econômico. Outra possibilidade de destinação do RSG consiste em desenvolver produtos cerâmicos com formulações aditivadas com o resíduo. Dentre as possíveis aplicações, citam-se telhas, blocos e placas cerâmicas de revestimento.

É recomendável a implementação de melhorias nos processos de tratamento de efluentes pelo setor industrial de semijoias folheadas de Juazeiro do Norte. Medidas que busquem métodos de produção mais limpa, com base na redução das emissões de efluentes e resíduos sólidos, na recuperação de metais-traço e no reúso de águas residuárias, poderão favorecer a sustentabilidade da atividade na região.

\section{AGRADECIMENTOS}

Os autores agradecem o apoio financeiro da Fundação Cearense de Apoio ao Desenvolvimento Científico e Tecnológico (FUNCAP), por meio do Programa de Bolsas de Produtividade em Pesquisa, Incentivo à Interiorização e Inovação Tecnológica (BPI - processo no BP4-00172-00080.01.00/20).

\section{CONTRIBUIÇÃO DOS AUTORES}

Figueirêdo, S. S. M.: metodologia, investigação, curadoria de dados, redação - rascunho original. Paula Filho, F. J.: conceituação, metodologia, obtenção de financiamento, supervisão, redação - revisão e edição. Pinto, L. A.: metodologia, investigação, validação. Oliveira, L. S.: metodologia, investigação, validação. Menezes, J. M. C.: validação, análise formal, escrita - revisão e edição.

\section{REFERÊNCIAS}

AGÊNCIA NACIONAL DE ÁGUAS (ANA). Panorama da qualidade das águas superficiais do Brasil: 2012. Agência Nacional de Águas. Brasília: ANA, 2012.

ALVES, L. C.; SEO, E. S. M. Caracterização do resíduo sólido proveniente do processo galvânico para valoração econômica ambiental. Engenharia Sanitária e Ambiental, v. 19, n. 4, p. 423-434, 2014. https://doi.org/10.1590/ S1413-41522014019000000637

ASSOCIAÇÃO BRASILEIRA DE NORMAS TÉCNICAS (ABNT). Armazenamento de resíduos sólidos perigosos. NBR 12.235. Rio de Janeiro: ABNT, 1992.

ASSOCIAÇÃO BRASILEIRA DE NORMAS TÉCNICAS (ABNT). Amostragem de resíduos sólidos. NBR 10.007. Rio de Janeiro: ABNT, 2004.

BRASIL. Lei no 12.305, de 2 de agosto de 2010. Institui a Política Nacional de Resíduos Sólidos; altera a Lei no 9.605, de 12 de fevereiro de 1998; e dá outras providências. Ministério do Meio Ambiente, Brasília, 2010.

BRASIL. Instituto Nacional de Metrologia, Qualidade e Tecnologia-INMETRO. Portaria no 43, de 22 de janeiro de 2016. Ministério do Desenvolvimento, Indústria e Comércio Exterior, Brasilia, 2016. Disponível em: http://www. inmetro.gov.br/legislacao/rtac/pdf/RTAC002383.pdf. Acesso em: O1 dez. 2019.
CEARÁ. COEMA no O2, de 02 de fevereiro de 2017. Dispõe sobre padrões e condições para lançamento de efluentes líquidos gerados por fontes poluidoras, revoga as portarias SEMACE n0154, de 22 de julho de 2002 e no11, de 05 de abril de 2011, e altera a portaria SEMACE n0151, de 25 de novembro de 2002. Conselho Estadual de Meio Ambiente. Resolução, Diário Oficial do Estado, Fortaleza, v. 9, n. 37, p. 56-61, 21 fev. 2017. Seção 3.

CHAER, G.; DINIZ, R. R. P.; RIBEIRO, E. A. A técnica do questionário na pesquisa educacional. Evidência, Araxá, v. 7, n. 7. p. 251-266, 2011

COMPANHIA DE GESTÃO DOS RECURSOS HÍDRICOS (COGERH). Plano de Monitoramento e Gestão dos Aquíferos da Bacia do Araripe. Estado do Ceará, Fortaleza, 2010. 272 p.

COSTA, C. T.; SANTOS, E. F; TAVARES, P. R. L. Potencialidade da contaminação por metais pesados procedente da indústria galvânica no município de Juazeiro do Norte/CE. XV Congresso Brasileiro de Águas Subterrâneas, Natal, 2008. Disponível em: https://aguassubterraneas.abas. org/asubterraneas/article/view/23808. Acesso em: 01 out. 2021.

FURTADO, M. R. Tratamento de superfície. Revista Química e Derivados, São Paulo, n. 416, 2003 
FURTADO, M. R. Co-processamento de resíduos. Revista Química e Derivados, São Paulo, n. 436, 2005.

INSTITUTO BRASILEIRO DE GEOGRAFIA E ESTATISTIICA (IBGE). Perfil Básico do Município de Juazeiro do Norte, 2017. Disponível em: https:// cidades.ibge.gov.br/brasil/ce/juazeiro-do-norte/panorama. Acesso em: 01 out. $2 \mathrm{O} 21$.

JACOBI, P. R.; BESEN, G. R. Gestão de resíduos sólidos em São Paulo: desafios da sustentabilidade. Estudos Avançados, São Paulo, v. 25, n. 71, 2011. http://doi.org/10.1590/S0103-40142011000100010

KURNIAWAN, T. A.; CHAN, G. Y. S.; WAl-HUNG, L.; BABEL, S. Physicochemical treatment techniques for wastewater laden with heavy metals. Chemical Engineering Journal, v. 118, p. 83-98, 2006. https://doi.org/10.1016/j. cej.2006.01.015

LIMA, T. S. A.; SALES, P. O.; SILVA, D. S.; ASSIS, C. T. R.; FONTENELE, S. B. Perfil industrial da região metropolitana do Cariri - Ceará. In: ANDRADE, D. F. (Ed.). Gestão da Produção em Foco. Vol. 13. Belo Horizonte: Poisson, 2018. https:// doi.org/10.5935/978-85-93729-54-6.2018B001

LOSITSKA, T. Innovative technologies: essence and importance of galvanic production development. Technology transfer: innovative solutions. Social Sciences and Humanities, 2018. Disponível em: http://eu-jr.eu/ttissh/article/ view/618/606. Acesso em: 26 dez. 2018.

NASCIMENTO, D. C.; CHACON, S. S. Sustentabilidade na Região Metropolitana do Cariri - RMC: análise a partir dos Objetivos de Desenvolvimento do Milênio - ODMs. Sociedade \& Natureza, Uberlândia, v. 28. n. 3, p. 443-456, 2016. http://doi.org/10.1590/1982-451320160309

OLIVEIRA, C. L. M.; PAULA FILHO, F. J.; MOURA, V. B.; FREITAS, D. M. G.; SANTIAGO, M. O. Characterization of Galvanic Sludges Waste Derived of the Metal Plating Industry from Cariri Region, Northeastern of Brazil. Materials Science Forum, v. 930, p. 541-545, 2018. https://doi.org/10.4028/ www.scientific.net/MSF.930.541

PAIS, A. R.; DINA, L. N.; ALVES, E. R.; REZENDE, H. C.; SILVA, L. A.; ALVES, V. A. Determinação de cádmio em bijuterias oriundas da China. Química Nova, V. 41, n. 10, p. 1218-1225, 2018. http://doi.org/10.21577/0100-4042.20170276
PASQUALINE, A. Estudo de caso aplicado à galvanoplastia. Dissertação (Mestrado em Engenharia de Produção) - Programa de Pós-Graduação em Engenharia de Produção, Universidade Federal de Santa Catarina, Florianópolis, SC, 2004.

PEREIRA NETO, A.; BRETZ, J. S.; MAGALHAES, F. S.; MANSUR, M. B.; ROCHA, S. D. F. Alternativas para o tratamento de efluentes da indústria galvânica. Engenharia Sanitária Ambiental, v. 13, n. 3, p. 263-270, 2008. http://doi. org/10.1590/S1413-41522008000300004.

PORRAS, A. C.; MONTENEGRO, D. L. C.; GRANADOS, E. A. O. Una alternativa limpia para el tratamiento de las aguas residuales galvánicas: revisión bibliográfica. Revista Ingenierías Universidad de Medellín, v. 8, n. 14, p. 3950, 2009.

QUEIROZ, I. S. Região metropolitana do cariri cearense, a metrópole fora do eixo. Mercator, Fortaleza, v. 13, n. 3, p. 93-104, 2014. http://doi.org/10.4215/ RM2014.1303.0007

ROCHA, S. D. F.; LINS, V. F. C.; SANTO, B. C. E. Aspectos do coprocessamento de resíduos em fornos de clínquer. Engenharia Sanitária Ambiental, v. 16, n. 1. p. 1-10, 2011. https://doi.org/10.1590/S1413-41522011000100003

STEFANO, F.; CRUZ, P. O novo mapa do consumo. Revista Exame, v. 1022. 2012. Disponível em: http://exame.abril.com.br/revista-exame/edicoes/1022/ noticias/o-novo-mapa-do-consumo. Acesso em: 12 jan. 2013.

TAVARES, P. R. L.; CASTRO, M. A. H.; COSTA, C. T. F.; SILVEIRA, J. G. P., ALMEIDA JUNIOR, F. J. B. Mapeamento da vulnerabilidade à contaminação das águas subterrâneas localizadas na Bacia Sedimentar do Araripe, Estado do Ceará, Brasil. Revista Escola de Minas, v. 62, n. 2, p. 227-236, 2009. https://doi. org/10.1590/S0370-44672009000200015

TELOEKEN, A.C. Utilização de lodo galvânico como matéria - prima em cerâmica vermelha: obtenção, caracterização de propriedades tecnológicas e aspectos ambientais. Dissertação (Mestrado em Engenharia de Minas, Metalurgia e de Materiais) - Universidade Federal do Rio Grande do Sul, Porto Alegre, RS, 2011.

UNITED STATES ENVIRONMENTAL PROTECTION AGENCY (USEPA). Test methods for evaluating solid waste, physical/chemical methods. In: UESPA. Office of Solid Waste, U.S. Washington, DC: Environmental Protection Agency, 1998. 